\title{
Bioengineered Islet Cell Transplantation
}

\section{Kevin Bellofatto ${ }^{1} \cdot$ Beat Moeckli $^{2} \cdot$ Charles-Henri Wassmer ${ }^{1,2} \cdot$ Margaux Laurent $^{2} \cdot$ Graziano Oldani $^{2} \cdot$ Axel Andres $^{2}$.

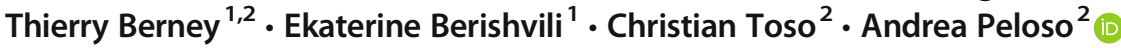

Accepted: 9 February 2021 / Published online: 13 March 2021

(C) The Author(s) 2021

\begin{abstract}
Purpose of Review $\beta$ cell replacement via whole pancreas or islet transplantation has greatly evolved for the cure of type 1 diabetes. Both these strategies are however still affected by several limitations. Pancreas bioengineering holds the potential to overcome these hurdles aiming to repair and regenerate $\beta$ cell compartment. In this review, we detail the state-of-the-art and recent progress in the bioengineering field applied to diabetes research.

Recent Findings The primary target of pancreatic bioengineering is to manufacture a construct supporting insulin activity in vivo. Scaffold-base technique, 3D bioprinting, macro-devices, insulin-secreting organoids, and pancreas-on-chip represent the most promising technologies for pancreatic bioengineering.

Summary There are several factors affecting the clinical application of these technologies, and studies reported so far are encouraging but need to be optimized. Nevertheless pancreas bioengineering is evolving very quickly and its combination with stem cell research developments can only accelerate this trend.
\end{abstract}

Keywords Diabetes · Beta cells · Islets of Langerhans · Islet transplantation · Biomaterials · Tissue engineering . Pancreas-on-chip $\cdot$ Regenerative medicine $\cdot 3 \mathrm{D}$ bioprinting

\section{Introduction}

Type 1 diabetes mellitus (T1DM) is a disease leading to an inability to maintain glucose homeostasis due to the autoimmune destruction of insulin-producing $\beta$ cells within islets of Langerhans $[1,2]$. Although the administration of exogenous insulin has revolutionized the treatment of T1DM, the disease remains associated with a significant long-term morbidity. The problem with exogenous insulin treatment is twofoldfirst, a lack of tight glucose control resulted in diabetes-related complications such as retinopathy, nephropathy, or myocardial infarction, and, secondly, intense insulin therapy is associated with more frequent hypoglycemia episodes [3, 4].

This article is part of the Topical Collection on Cellular Transplants

Andrea Peloso

Andrea.Peloso@unige.ch

1 Cell Isolation and Transplantation Center, Surgery, Geneva University Hospitals and University of Geneva, Geneva, Switzerland

2 Department of Visceral and Transplant Surgery, University of Geneva Hospital, Rue Gabrielle-Perret-Gentil 4,

1205 Geneva, Switzerland
A possible solution to both of these challenges is to replace $\beta$ cells through pancreas transplantation or cellular therapy. Although the outcomes of reported graft survival are excellent (defined as insulin independence) and reach $70 \%$ after 5 years of treatment [5], pancreas transplantation remains associated with a significant morbidity and mortality [6]. A minimally invasive alternative is the transplantation of isolated pancreatic islets. In the early 2000s, a group from Edmonton developed a revised protocol for islet transplantation that achieved sustained islet graft function in a series of T1DM patients [7]. Since then, tremendous progress has been made to improve islet function after transplantation, and has included a refinement of the isolation protocols and the design of steroid-free immunosuppression regimens $[6,8]$. However, the isolation and transplantation process still causes a significant strain on the islets leading to a graft function at 5 years of below $50 \%$ [1]. Islet isolation leads to a loss of vascularization and extracellular matrix. After intra-portal infusion, the current gold standard, islets are exposed to numerous insults such as hypoxic and hyperglycemia, toxic molecules from the dut-liver axis, and a very pro-inflammatory microenvironment $[9,10]$. Platelets bind to the islet surface and recruit immune cells that, in-turn, infiltrate and destroy the $\beta$ cells, reducing the 
available islet mass by up to $70 \%$ in the days following transplantation [11]. Furthermore, both whole pancreas transplantation and islet transplantation face the shortage of deceased donor organ availability.

In summary, the currently available $\beta$ cell replacement therapies only partially address the clinical need of T1DM patients for physiological glucose homeostasis regulation. At the same time, innovative new approaches for $\beta$ cell replacement have recently emerged, and methods that apply engineering tools to solve clinical challenges, so-called bioengineering, have transformed the medical field [12-15]. In this work, we review the progress in the field of pancreas replacement strategies. In particular, we review scaffold-based bioengineering, macro-devices, insulin-secreting organoids, 3Dbioprinting, and pancreas-on-chip (PoC) (Fig. 1).

\section{Scaffold-Based Bioengineering}

In recent years, many natural polymers (including decellularized biological matrices) have been proposed for the production of scaffolds. Biological scaffolds are biocompatible and composed by materials naturally mimicking the extracellular matrix (ECM). All the materials that we mention are used and designed to provide adequate immune protection, good vascularization, should reduce the use of immunosuppressants, and reproduce ECM that surrounds islets in order to create a similar environment as the pancreas. These materials, in combination with organoids and patient-derived cells, have been extensively explored in developmental research and show great potential for bench-to-beside translation toward personalized therapies.

Biological scaffolds are known for their biodegradability and biocompatibility and have been extensively used in T1DM research due to their versatility and their ability to be cross-linked with other molecules. This aims to better regulate parameters such as stiffness, porosity, degradation, or gelation kinetic [16].

Protein-based materials, including collagen, laminin, fibronectin, hyaluronic acid, and many other ECM-derived proteins are used for biological scaffold manufacturing. It has been intensively demonstrated that ECM molecules can improve the function and the viability of islets. The same was observed with $\beta$ cell and organoid function and viability in vivo and in vitro, especially with collagen I, III, and IV [17]. Collagen I is used in combination with laminin to improve islets or organoids, glucose-stimulated insulin secretion (GSIS), and viability. Collagen IV, when incorporated into PLG scaffold micro-pores, decreases apoptosis and augments viability, insulin secretion, and islet metabolic activity, and, if loaded with islets and transplanted on epididymal fat, it can potentially reduce the marginal mass, necessary to reverse the diabetic phenotype.

Alginate is a copolymer of a-L-guluronic acid and $\beta$-Dmannuronic acid. Alginate lacks ligands for cells adhesion. However, it can be functionalized with cations (Ca2+, $\mathrm{Sr} 2+$, and $\mathrm{Ba} 2+$ ) which bind mostly a-L-guluronic acid, which results in better rigidity and stability [18]. Alginate scaffolds are found in many formats, such as sheets, microcapsules, or threads and have been used to improve islet viability and function in vivo [19]. Human embryonic stem cell (hESC)-

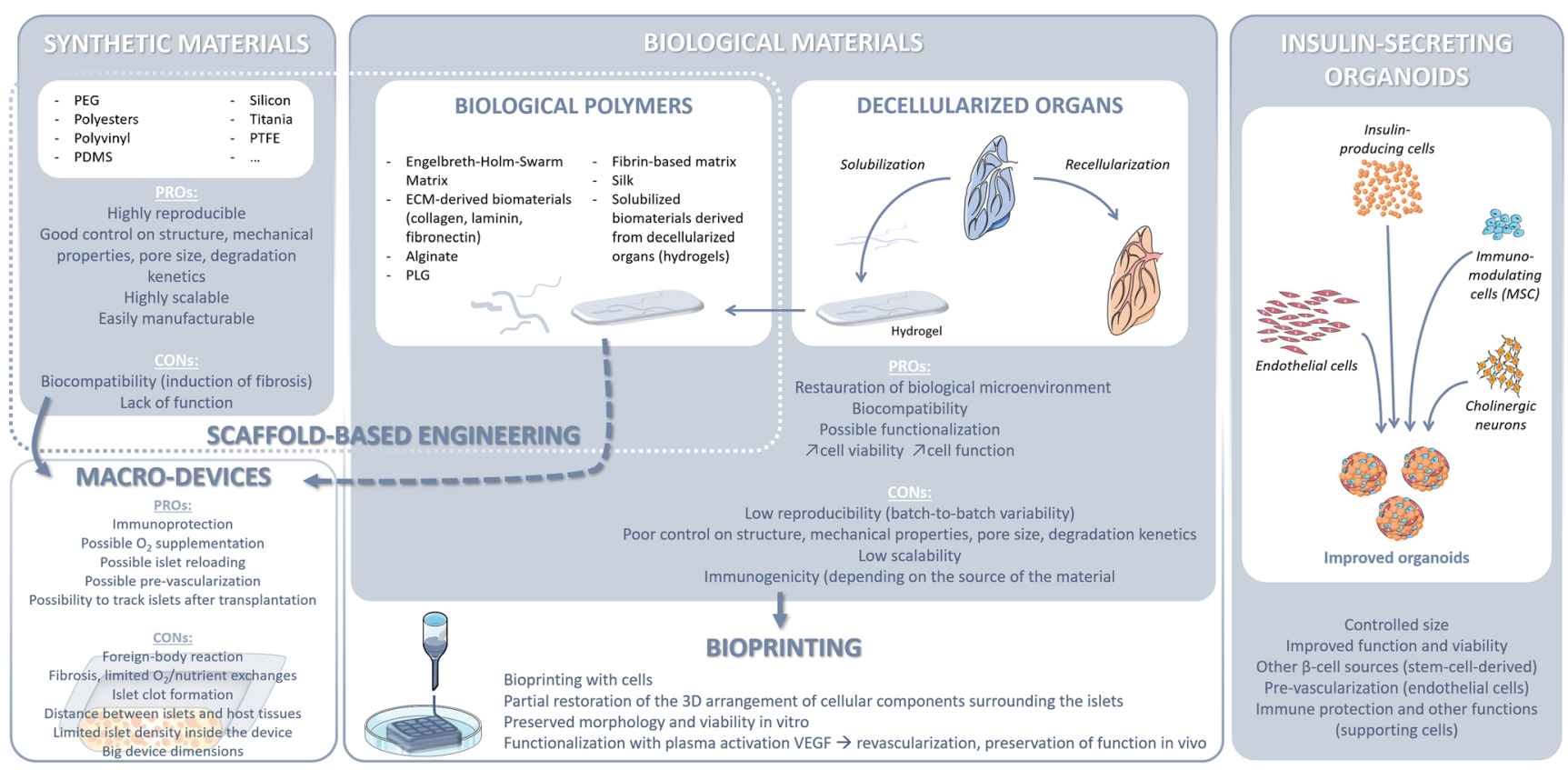

Fig. 1 Building blocks for the generation of a bioartificial pancreas. Scaffold-based engineering, macro-devices, 3D printing, insulin-secreting organoids, and organ-on-chip represent the most promising strategies for the achievement of a bioartificial pancreas 
derived $\mathrm{b}$ cell organoid (generated and differentiated on alginate scaffolds) have shown to significantly increase c-peptide levels compared to hESC cultured [20]. In vivo, alginate chemically bound with triazole-thiomorpholine dioxide, improves the function of transplanted islets. When tethered with adhesive peptides laminin-derived, and mixed with collagen IV and VI, alginate reduces cytokine-mediated cytotoxicity, improves islet viability and metabolic activity, and enhances GSIS.

Matrigel, cultrex, and geltrex are extracted from Engelbreth-Holm-Swarm (EHS) tumors and made using growth factor and protein from a basal membrane [21]. EHS extracts polymerize at $37{ }^{\circ} \mathrm{C}$ and can thus be used as a $3 \mathrm{D}$ scaffold for many applications such as the generation of organoids composed by human pluripotent stem cells (hPSC)-derived b cell organoids, fetal murine pancreatic progenitor cells, insulin-producing cells obtained by transdifferentiation, metastasis, and cancer growth [22••]. In addition, this material is mainly composed of proteins such as laminin, collagen IV, perlecan, and many other unique proteins in different concentrations (batch-dependent) [21].

\section{Decellularized Biomaterials}

Cell-on-scaffold technology is a well-explored technology intending to obtain functionally engineered pancreas using an acellular scaffold. Through decellularization, the cellular compartment from a human or an animal donor is removed while ECM molecules are preserved [23].

Different organs have been investigated for pancreas bioengineering; these include the pancreas [24•], liver [25], kidney [26], placenta [27], or lung [28] derived from murine [29], porcine [30], and human [31]. The resultant construct recapitulates the native organ characteristics and can be repopulated with different cell lines. Most of them are re-perfused using organoids, often in combination with another cell type (e.g., fibroblast, endothelial cells, mesenchymal stem cells). Perfused cells penetrate and adhere within the scaffold matrix, repopulating the decellularized organ structures. This can be achieved using ad hoc manufactured bioreactors and mediums created to mimic the physiological fluidics and environment. Furthermore, in some studies, the decellularized tissues and organs are further solubilized in order to obtain their single protein components to produce hydrogels [32] that can be further functionalized by the addition of glycosaminoglycans or proteoglycans. This results in a finer control of the hydrogel gelation kinetics [33].

Biological materials used for the generation of biological scaffolds are intrinsically biocompatible due to their ECMbased protein composition. Consequently, they provide (to the transplanted cells) support that is similar to cellular innate in situ environments, guaranteeing the restoration of the microenvironment at the transplantation site. These biological materials offer a functional support to transplanted cells and lead to improved viability and functionality. However, due to their animal origins, they are more difficult to reproduce on a consistent basis and they can be subjected to higher batch-tobatch variability. Structure, mechanical properties, pore size, and degradation kinetics are difficult to control, making these materials hardly scalable. Moreover, depending on their origin, these materials can elicit immunogenicity when transplanted [16].

Of interest, in 2019, Citro el al. [34••] proposed the lung as a favorable biological scaffold to support islet function. In their study, murine lung was decellularized and repopulated with human endothelial cells and pancreatic islets. Lung highdensity vasculature, similar to the pancreatic islet framework, sustained ex vivo and in vivo insulin function for up to 30 days. Considering current advancements in stem cells, such technology may allow for the fabrication of functional and customized endocrine organs.

Protein interaction maps aim to provide an in-depth view of the complex interplay between parenchymal and nonparenchymal cells. Asthana et al. [35••] recently reported important data on a mass spectrometry comparison between 15 human native and decellularized pancreata. A total of 935 proteins were detected in the native pancreas, whereas the pancreatic scaffolds were found to have only 613 proteins (counting for the $69 \%$ of the whole core matrisome). The pancreatic proteome has been preserved using a detergentfree decellularization protocol. Furthermore, for the first time, the pancreatic ECM (native, decellularized, and solubilized) has been profiled using functional and structural classes. The data from these studies provide significant insights regarding ECM application in hydrogels, bioinks, and medium additives.

\section{Bioprinting: 3D-Printed Vascularized Devices}

Bioprinting describes the process of building precise threedimensional (3D) structures that resemble naturally occurring tissues, layer by layer. 3D polymer printing was first developed in the 1980s and provided the necessary basis for later developments in bioprinting. In brief, monomers or oligomers were sequentially cross-linked through a photochemical reaction to form polymers and eventually 3D structures [36]. Nowadays, different forms of bioprinting exist, but all are based on three major components: (1) a bioink (biopolymer or cells) (2) that is sequentially deposited by extrusion, droplet, or laser-based dispensation (3) through a printing device into a 3D structure [37]. In 2002, a group at Wake Forest provided a striking example for the capabilities of bioprinting by constructing a partially functioning, artificial renal unit. This renal unit was created by seeding renal cells onto 
collagen-coated polycarbonate membranes and connecting them to collecting systems [38]. More recently, the same group developed a vascularized artificial uterus that was based on a bioprinted polymer scaffold seeded with uterine cells. This vascularized uterus was found to be capable of supporting rabbit pregnancies to term [39••].

At the same time, bioprinting has also been utilized in the engineering of islets; Marchioli et al. developed a 3D printed, macroporous alginate-based scaffold that can mimic a soft tissue and can be embedded with pancreatic islets (within the scaffold). The authors demonstrated that the viability and morphology of islets remained unaffected by the printing process [40]. Duin et al. used a similar approach and confirmed the viability of islets within the scaffold for up to 7 days [41•]. However, both studies showed that restricted mass diffusion and the absence of vascularization in the scaffold, despite its macroporous nature, impaired the functionality of the islets $[40,41]$. To address this issue, Farina et al. developed a bioprinted functionalized encapsulation device for subcutaneous implantation [42]. To stimulate neovascularization, authors treated the surface of the material using plasma activation and loaded the devices with different concentrations of vascular endothelial growth factor (VEGF). This improved the vascularization of the construct and the subcutaneously transplanted islets within the device remained functional for up to 10 weeks in an immunodeficient mouse model.

Microenvironment provides cues for function and survival of islets being also vital for $\beta$ cells to fulfill their physiologic task; unfortunately, the islet isolation process disrupts this precious microenvironment $[43,44]$ and leaves the islets without cellular support. Bioprinting offers the possibility of partially restoring the $3 \mathrm{D}$ arrangement of cellular components that should surround pancreatic islets. Liu et al. developed a co-axial bioprinter that allows the printing of different cellular components in separated layers onto a macroporous construct [45]. The authors chose a tubular structure arranged in an array; islets are located in the core and supportive cells (endothelial or $\mathrm{T}$ regulatory cells) in the outer shell.

Taken together, these studies provide important groundwork for potentially using bioprinting to engineer transplantable islet-containing constructs. Combining the knowledge gained from the different approaches might allow for the development of a preclinical device that achieves satisfactory glucose regulation; however, at this point, bioprinting remains far from reaching clinical applicability.

\section{Macro-Devices}

Islets macro-encapsulation consists of enclosing a large number of islets inside a biological or synthetic device that can be placed in communication with either the vasculature or extravascularly. The first attempts of macro-encapsulation date back to the 1950s and now, 70 years later, the aim remains the same: islet immunoisolation using a physical barrier in order to avoid immunosuppression and to be able to transplant xeno- or stem cell-derived insulin-secreting cells [46]. The principle is creating a semipermeable membrane that allows nutrients and oxygen exchange while preventing the passage of molecules and cells from the immune system. One major drawback of encapsulation is the reduced oxygenation of islets caused by the membrane, which increases the distance between vessels and islets that are already suffering from hypoxic stress. In fact, it has been demonstrated that cell necrosis occurs when the distance with the nearest vessel exceeds 150 $200 \mu \mathrm{m}$ [47].

Those promising features have been counter balanced by the first in vivo results, which revealed the development of fibrosis around devices and inconsistent results [48]. In fact, several issues hamper the development of macro-devices. First, synthetic materials are mostly used and have been associated with the development of foreign body reactions resulting in fibrosis, limit exchanges of oxygen and nutrients, and preclude hormone secretion. Secondly, in contrast with nano- and micro-encapsulation where the surface to volume ratio is maximized, in macro-encapsulation, islet density should not exceed $5-10 \%$ of the total volume of the device in order to ensure sufficient oxygenation and nutrient diffusion [49]. In addition, it has been demonstrated that the diameter of the device should not be more than a few hundred microns to prevent cell necrosis [50]. Thirdly, islets have a tendency to form clusters at the center of the device. This not only increases the risk of necrosis but also delays the response to glucose variations in the blood because of the distance between islets and blood vessels [46]. Finally, immunoisolation of the encapsulated cells requires a semipermeable membrane that can prevent vessel growth inside the device. This was observed in the clinical trial with the PECEncap (VC-01) from ViaCyte where encapsulated pancreatic endodermal cells were protected from the immune system, but the lack of intra-device vascularization and the presence of fibrosis around the device was observed $[51 \bullet \cdot]$. With this knowledge, great efforts are being made to overcome these issues.

The complexity of generating an encapsulation device is to find the right material that will be biocompatible, have minor or no fibrosis development, and allow nutrient exchanges while offering immunoisolation. Biological materials such as alginate or ECM-derived components are good candidates in terms of biocompatibility and induce less foreign body reactions compared to synthetic materials. However, they present more inconsistency between batches in terms of composition and endotoxin levels, which prevents the generation of homogenous encapsulation devices. In addition, pore sizes, membrane thickness, and the degree of porosity cannot be controlled as well as with manufactured synthetic materials. 
Because the degree of porosity can promote vascularization, reduce fibrosis development, and can modulate the immune response, a rigorous and reliable scaffold generation technique is essential $[52,53]$.

The development of large and flat devices has allowed for an increase in the number of encapsulated islets by increasing the surface and reducing the length of needed oxygen diffusion. This was demonstrated by Storrs et al. with the development of the Islet Sheet Device, an alginate sheet that is $250-\mu \mathrm{m}$ thick and contains islets sutured on the omentum of pancreatectomized dogs in an allogenic model [54]. Although blood glucose was lowered after transplantation, animals were still found to have impaired glucose metabolism. In addition, after 84 days, the sheets were found folded in the omentum within a hard fibrotic capsule. It is noteworthy to mention that in order to respond to patient metabolic demands, an important number of islets are needed.

One way to avoid the need for a large device is to improve the vascularization and/or the oxygenation at the transplantation site. Induction of pre-vascularization at the transplantation site has revealed that it is possible to improve this environment in animals [55], and is currently being assessed in human clinical trials with the Sernova's Cell Pouch [56]. Other approaches have been developed such as the delivery of growth factors to promote rapid vascularization [57] [58] by using implantable oxygen-releasing materials $[59,60]$ or using oxygen-carrying devices such as the Beta- $\mathrm{O}_{2}$, which is currently in an on-going human clinical trial [56]. This device is composed of (i) a chamber separated into two modules, (ii) a peripheral module containing human islets, and (iii) a central module filled with oxygen with ports for daily oxygen reloading. The first results of the human study demonstrated preserved functioning of the encapsulated islets for up to 10 months without immunosuppression. However, no significant clinical improvements were measured with regards to the disease [58].

Macro-devices for islet transplantation are valuable and will clearly shape the future in the field. By shedding insulin-secreting cells from the immune system and allowing the transplantation to occur at a different site than the liver, it will allow the use of alternative sources of insulin secretin cells (as mentioned above). However, the ideal material and the best membrane characteristics have yet to be determined.

\section{Insulin-Secreting Organoids}

Insulin-secreting organoids represent $3 \mathrm{D}$ cell aggregates that have the capacity to secrete insulin. They are generated by the aggregation of several cells, either from the same type (e.g. $\beta$ cell) or through a combination of different cell types [15].

Islets present different sizes and shapes. It has been demonstrated that smaller islets usually performed and survived better than larger islets in vitro and in vivo [61, 62] probably due central core necrosis in the bigger islets. Furthermore, the re-aggregation of dissociated islets into smaller and homogeneous pseudo-islets (PI) has improved function and viability compared to that of native islets $[63,64]$. In addition to human-isolated or animal-isolated islets, any other type of insulin-secreting cell sources mentioned above can be used to generate organoids and offer a wide range of options to overcome the shortage of primary islets. In addition to the possibility of controlling the size and composition of PI, organoid generation allows to improve PI functions by incorporating accessory cells with supportive characteristics. For instance, endothelial cells $[65,66]$ and cholinergic neurons [67] have been used to improve revascularization and innervation of organoids. As mentioned above, inflammatory and adaptive immunity reactions are very detrimental to transplanted islets. The concept of encapsulation, which aimed to protect the islet by preventing its contact with the immune system, was found to be successful but at the price of a reduction in nutrients and oxygen supply. By adding cells with immunomodulatory and anti-inflammatory properties to the PI, there is the possibility that an immune-privileged environment is created that is suitable for long-term function and survival. This has been successfully performed in animals by co-culturing insulin-secreting cells with mesenchymal stem cells [68, 69] and amniotic epithelial cells [70, 71], demonstrating improved function and viability in vitro and in vivo.

Insulin-secreting organoids should not be considered to be an alternative approach from encapsulation. On the contrary, insulin-secreting organoids should be considered to be complementary and serve as building blocks, incorporated in a macro-device, for the generation of a bioartificial pancreas.

\section{Pancreas-on-Chip Bioengineering}

With the main purpose to investigate potential chemical and drug side effects, a lot of in vitro model systems have been developed. Organ-on-chip technology is rapidly emerging as a game-changing technology in basic research, and pancreason-chip (PoC) has been proposed as a new generation of in vitro model. A study led by Leclerc et al. showed that insulin-producing beta cells could be integrated in an isleton-a-chip device allowing to perform screening of the insulin-producing cells before a transplant can be made into a patient [72]. Besides, the islet-on-a-chip allows them to test insulin-stimulating compounds and facilitates the study of the diabetes biology.

Chip configuration essentially depends on the type of organs' function that needs to be investigated. PoC has been proposed as a pancreatic function microfluidic monitoring tool, mimicking in vivo fluid flow when connected to a specific perfusion system. Specifically, the authors demonstrated 
how we could exploit this technology to deeply understand cell-cell signaling in pathological conditions [73]. Furthermore, Glieberman et al. have proposed a chip that can stimulate pancreatic islets automatically through an immunofluorescent glucose tracking and an in situ insulin immunoassay [74•]. This microfluidic setup allows to test "onchip" islet viability, composition, and metabolite release. More importantly, studies have shown that perfusing culture systems can not only enhance islet survival but also show how precise a fluid control should be. In 2019, Jun et al. [75••] reported that a chip-based platform is able to mimic interstitial flow levels via an osmosis-driven low-speed control (1.54$5.04 \mu \mathrm{m} / \mathrm{s}$ ) reducing the shear stress on islets. This platform allows a long-term islet culture (up to 30 days) with improved insulin release, reconstitution of ECM, and preservation of endothelial framework. Such platform could be easily translated to clinic and used to refine currently available islet tests performed prior transplantation (principally based just on an in vitro GSIS assay).

Post-isolation islet quality remains a principal aim for $\mathrm{PoC}$ research. Different research groups have been developing chip-based microfluidic platforms able to evaluate islet function through intracellular $\mathrm{Ca}^{2+}$ levels $[76,77]$ or oxygen consumption rate (OCR) [78-80]. In addition to OCR, the ATP/ ADP ratio has been proposed by Goto et al. as a novel predictive assay for islets' microfluidic quality assessment [81].

Microfluidic devices designed with see-through materials have been developed to provide an in vitro "live" imaging of cultured islets during all the most important stages such as glucose response, stress stimuli, and death pathways. In particular, Zbinden et al. have combined PoC and Raman imaging technology [82]. This strategy allowed us to study the biphasic response of human pseudo-islets as well as their mitochondrial activity certifying in situ monitoring and a consistent quantifying.

Organ-on-chip technology has recently evolved from a single organ to several organs connected together through microfluidic systems, thus moving from organ-on-chip technology to multi-organ-on-chip technology, also named bodyon-chip [83]. With the attempt to co-culture pancreatic and liver tissue, Bauer et al. and colleagues developed a multiorgan-on-chip system coupling human hepatic organoids and human islets [84]. Their platform provided important insights concerning islet-liver interactions and demonstrated a feedback loop between liver spheroids and pancreatic islets. More in details, the authors showed that while insulin release from pancreatic islets increased, there was a concomitant augmentation for its uptake in the liver spheroids. Conversely, a glucose concentration lowering in the chip system led to an immediate cessation of insulin release from the pancreatic islets. Of great interest, the system enables these two cell populations to be co-cultured for up to 15 days, allowing quantifications and essays to be repeated at different time points.
PoC technology can be also declined to reconstitute the innate islets vascular compartment. Indeed islets are heavily vascularized to promote glucose sensing, metabolite exchange, and quick insulin release. During islet isolation, an important portion of the native vascular framework is lost, making islets more susceptible to hypoxia and potentially reducing their endocrine capabilities. With this perspective, the development of a multi-organ-on-chip connecting a dedicated vascular compartment with pancreatic islets can replicate the physiological capillary/islet surface. The internalization of a functional vascular inside a chip is currently very difficult to achieve due to the micro dimensions of microfluidics channels. Just a few organ-on-a-chip systems have thus far sought to recreate vasculature's organ-specific dynamics. Specifically in 2017, the Bureau research group [85.] proposed a mono-microfluidic channel coated with a layer of endothelial cells to examine the regulation of glycosaminoglycan interactions with erythrocytes. In particular, this platform allowed the direct tracking of the most important component of whole blood such as red blood cells, leukocytes, or platelets. Furthermore, the authors demonstrated cellular response to hydrodynamic resistance or other biochemical stimuli.

Despite this field still being in its infancy, in recent years, pancreas-on-chip technology is becoming increasingly accessible and robust.

\section{Conclusions}

Although whole pancreas and islet transplantation remain the best therapies for T1DM, regenerative medicine and pancreas bioengineering strategies hold the potential to optimize the current strategies for $\beta$ cell replacement. In this review, the latest advances are discussed, covering the most promising tools for pancreatic tissue engineering. In order to address the current limitations, especially related to long-term islets' viability and functionality, all the strategies proposed need to be perfected and refined. We believe that the rapid advancement of stem cell research may accelerate the evolution of pancreatic bioengineering toward its unprecedentedly biomedical application [86•].

Abbreviations T1DM, Type 1 diabetes mellitus; $\beta$ cells, Beta cells; $E C M$, Extracellular matrix; $h E S C$, Human embryonic stem cell; GSIS, Glucose-stimulated insulin secretion; EHS, Engelbreth-Holm-Swarm; hPSC, Human pluripotent stem cells; PI, Pseudo-islets; PoC, Pancreason-chip

Acknowledgements We thank Fanny Lebreton (Cell Isolation and Transplantation Center, Surgery, Geneva University Hospitals and University of Geneva, Geneva, Switzerland) for the graphical illustration support. 
Funding Open Access funding provided by Université de Genève.

\section{Declarations}

Conflict of interest The authors declare no competing interests.

Open Access This article is licensed under a Creative Commons Attribution 4.0 International License, which permits use, sharing, adaptation, distribution and reproduction in any medium or format, as long as you give appropriate credit to the original author(s) and the source, provide a link to the Creative Commons licence, and indicate if changes were made. The images or other third party material in this article are included in the article's Creative Commons licence, unless indicated otherwise in a credit line to the material. If material is not included in the article's Creative Commons licence and your intended use is not permitted by statutory regulation or exceeds the permitted use, you will need to obtain permission directly from the copyright holder. To view a copy of this licence, visit http://creativecommons.org/licenses/by/4.0/.

\section{References}

Papers of particular interest, published recently, have been highlighted as:

- Of importance

•- Of major importance

1. Vantyghem MC, de Koning EJP, Pattou F, Rickels MR. Advances in $\beta$-cell replacement therapy for the treatment of type 1 diabetes. Lancet. 2019;394:1274-85. https://doi.org/10.1016/S01406736(19)31334-0.

2. Banting FG, Best CH, Collip JB, Campbell WR, Fletcher AA. Pancreatic extracts in the treatment of diabetes mellitus. Can Med Assoc J. 1922;12:141-6.

3. Holman RR, Paul SK, Bethel MA, Matthews DR, Neil HA. 10-year follow-up of intensive glucose control in type 2 diabetes. N Engl J Med. 2008;359:1577-89. https://doi.org/10.1056/ NEJMoa0806470.

4. Control D, Complications Trial Research Group, Nathan DM, Genuth $\mathrm{S}$, Lachin J, Cleary P, et al. The effect of intensive treatment of diabetes on the development and progression of long-term complications in insulin-dependent diabetes mellitus. N Engl J Med. 1993;329:97786. https://doi.org/10.1056/NEJM199309303291401.

5. Gruessner AC, Gruessner RW. Long-term outcome after pancreas transplantation: a registry analysis. Curr Opin Organ Transplant. 2016;21:377-85. https://doi.org/10.1097/MOT.0000000000000331.

6. Niclauss N, Meier R, Bedat B, Berishvili E, Berney T. Beta-Cell replacement: pancreas and islet cell transplantation. Endocr Dev. 2016;31:146-62. https://doi.org/10.1159/000439412.

7. Shapiro AM, Lakey JR, Ryan EA, Korbutt GS, Toth E, Warnock GL, et al. Kneteman NM, Rajotte RV. Islet transplantation in seven patients with type 1 diabetes mellitus using a glucocorticoid-free immunosuppressive regimen. N Engl J Med. 2000;343:230-8. https://doi.org/10.1056/NEJM200007273430401.

8. Gamble A, Pepper AR, Bruni A, Shapiro AMJ. The journey of islet cell transplantation and future development. Islets. 2018;10:80-94. https://doi.org/10.1080/19382014.2018.1428511.

9. Merani S, Toso C, Emamaullee J, Shapiro AM. Optimal implantation site for pancreatic islet transplantation. Br J Surg. 2008;95: 1449-61. https://doi.org/10.1002/bjs.6391.
10. Carlsson PO, Palm F, Andersson A, Liss P. Markedly decreased oxygen tension in transplanted rat pancreatic islets irrespective of the implantation site. Diabetes. 2001;2001(50):489-95. https://doi. org/10.2337/diabetes.50.3.489.

11. Sakata N, Hayes P, Tan A, Chan NK, Mace J, Peverini R, et al. MRI assessment of ischemic liver after intraportal islet transplantation. Transplantation. 2009;87:825-30. https://doi.org/10.1097/TP. 0b013e318199c7d2.

12. Mott R, Fabbiano S, Levinson R, Emambokus N. Editorial: bioengineering and metabolism. Cell Metab. 2019;29:505. https://doi. org/10.1016/j.cmet.2019.02.010.

13. Maoz BM, Herland A, FitzGerald EA, Grevesse T, Vidoudez C, Pacheco AR, et al. A linked organ-on-chip model of the human neurovascular unit reveals the metabolic coupling of endothelial and neuronal cells. Nat Biotechnol. 2018;36:865-74. https://doi. org/10.1038/nbt.4226.

14. Murphy SV, Atala A. 3D bioprinting of tissues and organs. Nat Biotechnol. 2014;32:773-85. https://doi.org/10.1038/nbt.2958.

15. Wassmer CH, Lebreton F, Bellofatto K, Bosco D, Berney T, Berishvili E. Generation of insulin-secreting organoids: a step toward engineering and transplanting the bioartificial pancreas. Transpl Int. 2020;33:1577-88. https://doi.org/10.1111/tri.13721.

16. Kratochvil MJ, Seymour AJ, Li TL, Pașca SP, Kuo CJ, Heilshorn SC. Engineered materials for organoid systems. Nat Rev Mater. 2019;4:606-22.

17. Llacua LA, Faas MM, de Vos P. Extracellular matrix molecules and their potential contribution to the function of transplanted pancreatic islets. Diabetologia. 2018;61:1261-72. https://doi.org/10.1007/ s00125-017-4524-8.

18. Pawar SN, Edgar KJ. Alginate derivatization: a review of chemistry, properties and applications. Biomaterials. 2012;33:3279-305. https://doi.org/10.1016/j.biomaterials.2012.01.007.

19. Zimmermann H, Shirley SG, Zimmermann U. Alginate-based encapsulation of cells: past, present, and future. Curr Diab Rep. 2007;7:314-20. https://doi.org/10.1007/s11892-007-0051-1.

20. Richardson T, Kumta PN, Banerjee I. Alginate encapsulation of human embryonic stem cells to enhance directed differentiation to pancreatic islet-like cells. Tissue Eng Part A. 2014;20:3198-211. https://doi.org/10.1089/ten.TEA.2013.0659.

21. Hughes CS, Postovit LM, Lajoie GA. Matrigel: a complex protein mixture required for optimal growth of cell culture. Proteomics. 2010;10:1886-90. https://doi.org/10.1002/pmic.200900758.

22.• CJM L, Williams Giuliani N, Balak J, Ringnalda F, van Gurp L, Huch M, et al. Expansion of adult human pancreatic tissue yields organoids harboring progenitor cells with endocrine differentiation potential. Stem Cell Rep. 2018;10:712-24. https://doi.org/10.1016/ j.stemcr.2018.02.005 The authors describe the 3D culture system supporting the expansion of adult human pancreatic tissue with the generation of a cell subpopulation with progenitor characteristics. These cells express important transcription factors (PDX1, PTF1A, CPA1, and MYC) as well as endocrine differentiation potential. Final data suggest how adult pancreatic tissue, when appropriately cultured in a tridimensional system, could harbour high aldehyde dehydrogenase activity (ALDH ${ }^{\text {hi }}$ ) cell subpopulation suggesting their potential for $\beta$ cell therapy.

23. Croce S, Peloso A, Zoro T, Avanzini MA, Cobianchi L. A Hepatic scaffold from decellularized liver tissue: food for thought. Biomolecules. 2019;9:813. https://doi.org/10.3390/biom9120813.

24. Sackett SD, Tremmel DM, Ma F, Feeney AK, Maguire RM, Brown ME, et al. Extracellular matrix scaffold and hydrogel derived from decellularized and delipidized human pancreas. Sci Rep. 2018;8:10452. https://doi.org/10.1038/s41598-018-28857-1 This study presents novel decellularization protocols (spindecellularization, chemical decellularization, and delipidation) to obtain acellular human pancreatic scaffold. Additionally, for 
the first time, human acellular ECM has been used to produce a manufactured 3D scaffold and hydrogel used to tissue culture, transplantation, and proteomic applications.

25. Xu T, Zhu M, Guo Y, Wu D, Huang Y, Fan X, et al. Threedimensional culture of mouse pancreatic islet on a liver-derived perfusion-decellularized bioscaffold for potential clinical application. J Biomater Appl. 2015;30:379-87. https://doi.org/10.1177/ 0885328215587610 .

26. Willenberg BJ, Oca-Cossio J, Cai Y, Brown AR, Clapp WL, Abrahamson DR, et al. Repurposed biological scaffolds: kidney to pancreas. Organogenesis. 2015;11:47-57. https://doi.org/10. 1080/15476278.2015.1067354.

27. Bellofatto K, Wassmer C, Lebreton F, Lavallard V, Brioudes E, David C-D, et al. Bioartificial endocrine pancreas generated from decellularized human placenta for type-1 diabetes treatment. Transplantation. 2019;103:S2-S14.

28. Abualhassan N, Sapozhnikov L, Pawlick RL, Kahana M, Pepper AR, Bruni A, et al. Lung-Derived microscaffolds facilitate diabetes reversal after mouse and human intraperitoneal islet transplantation. PLoS One. 2016;11:e0156053. https://doi.org/10.1371/journal. pone. 0156053 .

29. Guruswamy Damodaran R, Vermette P. Decellularized pancreas as a native extracellular matrix scaffold for pancreatic islet seeding and culture. J Tissue Eng Regen Med. 2018;12:1230-7. https://doi.org/ 10.1002/term.2655.

30. Kuna VK, Kvarnström N, Elebring E, Holgersson SS. Isolation and decellularization of a whole porcine pancreas. J Vis Exp. 2018;10: 58302. https://doi.org/10.3791/58302.

31. Peloso A, Urbani L, Cravedi P, Katari R, Maghsoudlou P, Fallas $\mathrm{ME}$, et al. The human pancreas as a source of protolerogenic extracellular matrix scaffold for a new-generation bioartificial endocrine pancreas. Ann Surg. 2016;264:169-79. https://doi.org/10.1097/ SLA.0000000000001364.

32. Saldin LT, Cramer MC, Velankar SS, White LJ, Badylak SF. Extracellular matrix hydrogels from decellularized tissues: Structure and function. Acta Biomater. 2017;9:1-15. https://doi. org/10.1016/j.actbio.2016.11.068.

33. Brightman AO, Rajwa BP, Sturgis JE, McCallister ME, Robinson JP, Voytik-Harbin SL. Time-lapse confocal reflection microscopy of collagen fibrillogenesis and extracellular matrix assembly in vitro. Biopolymers. 2000;54:222-34. https://doi.org/10.1002/ 1097-0282(200009)54:3<222::AID-BIP80>3.0.CO;2-K

34.• Citro A, Moser PT, Dugnani E, Rajab TK, Ren X, EvangelistaLeite $\mathrm{D}$, et al. Biofabrication of a vascularized islet organ for type 1 diabetes. Biomaterials. 2019;199:40-51. https://doi.org/10.1016/j. biomaterials.2019.01.035 This article describes for the first time the use of decellularized lung tissue as the site for islet implantation. The specificity of the extracellular matrix is questioned, showing that there is an overlap of the most important components between pancreatic and pulmonary ECM. Furthermore, the authors describe a remarkable correspondence in the vascular outline between pancreas and lung. The vascularized islet organ (VIO) has been transplanted in diabetic mice achieving higher insulin release compared to standard islets up to 30 days. Such platform revolutionized the concept of regenerative medicine where a bioengineered organ is traditionally manufactured using ECM deriving from the same organ. Studying and taking advantage of the similarities between different organ ECM could pave the way toward new interesting organ-bioengineered crossovers.

35.• Asthana A, Tamburrini R, Chaimov D, Walker SJ, Van Dyke M, Tomei A, et al. Comprehensive characterization of the human pancreatic proteome for bioengineering applications. Biomaterials. https://doi.org/10.1016/j.biomaterials.2020.120613 This study deeply investigated the human pancreatic tissue by combining mass spectrometry (MS) and multiplex ELISA and achieving the molecular fingerprint of the native human pancreas. Additionally, human pancreata has been decellularized via a novel detergent-free protocol and ECM-derived scaffold have been analyzed. Finally, for the first time, the gel derived from the extracellular matrix was also profiled. Given the results provide crucial insights for regenerative medicine and organ bioengineering field. The authors not only provide a comparison with traditional scaffolds but also detail the effects of their decellularization protocol on the extracellular cell matrix and the resulting hydrogel.

36. Melchels FP, Feijen J, Grijpma DW. A review on stereolithography and its applications in biomedical engineering. Biomaterials. 2010;31:6121-30. https://doi.org/10.1016/j.biomaterials.2010.04. 050 .

37. Leberfinger AN, Dinda S, Wu Y, Koduru SV, Ozbolat V, Ravnic DJ, et al. Bioprinting functional tissues. Acta Biomater. 2019;95: 32-49. https://doi.org/10.1016/j.actbio.2019.01.009.

38. Lanza RP, Chung HY, Yoo JJ, Wettstein PJ, Blackwell C, Borson $\mathrm{N}$, et al. Generation of histocompatible tissues using nuclear transplantation. Nat Biotechnol. 2002;20:689-96. https://doi.org/10. 1038/nbt703.

39.• Magalhaes RS, Williams JK, Yoo KW, Yoo JJ, Atala A. A tissueengineered uterus supports live births in rabbits. Nat Biotechnol. 2020;38:1280-7. https://doi.org/10.1038/s41587-020-0547-7 This article looked at a bioengineered scaffold repairing the uterus and supports live births in rabbits. Reported data are highly significant with great potential for future human application, and in particular, for women suffering infertility. This study confirms how 3D-printing represents an outstanding tool for scaffold manufacturing.

40. Marchioli G, van Gurp L, van Krieken PP, Stamatialis D, Engelse M, van Blitterswijk CA, et al. Fabrication of three-dimensional bioplotted hydrogel scaffolds for islets of Langerhans transplantation. Biofabrication. 2015;7:025009. https://doi.org/10.1088/17585090/7/2/025009.

41. Duin S, Schütz K, Ahlfeld T, Lehmann S, Lode A, Ludwig B, et al. 3D Bioprinting of functional islets of Langerhans in an alginate/ methylcellulose hydrogel blend. Adv Health Mater. 2019;8: e1801631. https://doi.org/10.1002/adhm.201801631. This study presents pancreatic islet encapsulation in 3D-printed alginate and methylcellulose hydrogel structures. The loaded islets maintained their viability and functionality, normally releasing insulin and glucagon.

42. Farina M, Ballerini A, Fraga DW, Nicolov E, Hogan M, Demarchi $\mathrm{D}$, et al. 3D Printed vascularized device for subcutaneous transplantation of human islets. Biotechnol J. 2017;12. https://doi.org/10. 1002/biot.201700169.

43. Almaça J, Caicedo A, Landsman L. Beta cell dysfunction in diabetes: the islet microenvironment as an unusual suspect. Diabetologia. 2020;63:2076-85. https://doi.org/10.1007/ s00125-020-05186-5.

44. Brissova M, Aamodt K, Brahmachary P, Prasad N, Hong JY, Dai $\mathrm{C}$, et al. Islet microenvironment, modulated by vascular endothelial growth factor-A signaling, promotes $\beta$ cell regeneration. Cell Metab. 2014;19:498-511. https://doi.org/10.1016/j.cmet.2014.02. 001.

45. Liu X, Carter SD, Renes MJ, Kim J, Rojas-Canales DM, Penko D, et al. Development of a coaxial 3D printing platform for biofabrication of implantable islet-containing constructs. Adv Health Mater. 2019;8:e1801181. https://doi.org/10.1002/adhm. 201801181.

46. Song S, Roy S. Progress and challenges in macroencapsulation approaches for type 1 diabetes (T1D) treatment: Cells, biomaterials, and devices. Biotechnol Bioeng. 2016;113:1381-402. https://doi. org/10.1002/bit.25895. 
47. Thomlinson RH, Gray LH. The histological structure of some human lung cancers and the possible implications for radiotherapy. $\mathrm{Br}$ J Cancer. 1955;9:539-49. https://doi.org/10.1038/bjc.1955.55.

48. de Vos P, Marchetti P. Encapsulation of pancreatic islets for transplantation in diabetes: the untouchable islets. Trends Mol Med. 2002;8:363-6. https://doi.org/10.1016/s1471-4914(02)02381-x.

49. Scharp DW, Marchetti P. Encapsulated islets for diabetes therapy: history, current progress, and critical issues requiring solution. Adv Drug Deliv Rev. 2014;67-68:35-73. https://doi.org/10.1016/j.addr. 2013.07.018.

50. Dulong JL, Legallais C. A theoretical study of oxygen transfer including cell necrosis for the design of a bioartificial pancreas. Biotechnol Bioeng. 2007;96:990-8. https://doi.org/10.1002/bit. 21140.

51.• Henry R, Wilensky J, Shapiro AMJ, Peter A, Roep B, et al. Initial clinical evaluation of VC-01TM combination product-a stem cell-derived islet replacement for type 1 diabetes (T1D). Diabetes. 2018;67(Supplement 1):138. https://doi.org/10.2337/db18-138-OR This is the first clinical trial exploring the use of an immunoprotective macro-device loaded with pancreatic endodermal cells. Although the immune-protective nature of the encapsulation device and safety of this stem cell-derived product have been evidenced, preliminary results also show important hurdles to overcome such as a reduced tissue engraftment and transformation into insulin-producing cells.

52. Lee S, Choi J, Shin S, Im YM, Song J, Kang SS, et al. Analysis on migration and activation of live macrophages on transparent flat and nanostructured titanium. Acta Biomater. 2011;7:2337-44. https:// doi.org/10.1016/j.actbio.2011.01.006

53. Madden LR, Mortisen DJ, Sussman EM, Dupras SK, Fugate JA, Cuy JL, et al. Proangiogenic scaffolds as functional templates for cardiac tissue engineering. Proc Natl Acad Sci U S A. 2010;24(107):15211-6. https://doi.org/10.1073/pnas.1006442107.

54. Storrs R, Dorian R, King SR, Lakey J, Rilo H. Preclinical development of the Islet sheet. Ann N Y Acad Sci. 2001;944:252-66. https://doi.org/10.1111/j.1749-6632.2001.tb03837.x.

55. Pepper AR, Gala-Lopez B, Pawlick R, Merani S, Kin T, Shapiro AM. A prevascularized subcutaneous device-less site for islet and cellular transplantation. Nat Biotechnol. 2015;33:518-23. https:// doi.org/10.1038/nbt.3211.

56. Sernova announces clinical trial investigator presentation at the ASTS 21st winter symposium; https://www.sernova.com/press/

57. Zisch AH, Lutolf MP, Ehrbar M, Raeber GP, Rizzi SC, Davies N, et al. Cell-demanded release of VEGF from synthetic, biointeractive cell ingrowth matrices for vascularized tissue growth. FASEB J. 2003;17:2260-2. https://doi.org/10.1096/fj.02-1041fje.

58. Ludwig B, Reichel A, Steffen A, Zimerman B, Schally AV, Block NL, et al. Transplantation of human islets without immunosuppression. Proc Natl Acad Sci U S A. 2013;110:19054-8. https://doi.org/ 10.1073/pnas.1317561110.

59. Harrison BS, Eberli D, Lee SJ, Atala A, Yoo JJ. Oxygen producing biomaterials for tissue regeneration. Biomaterials. 2007;28:462834. https://doi.org/10.1016/j.biomaterials.2007.07.003

60. Oh SH, Ward CL, Atala A, Yoo JJ, Harrison BS. Oxygen generating scaffolds for enhancing engineered tissue survival. Biomaterials. 2009;30:757-62. https://doi.org/10.1016/j. biomaterials.2008.09.065.

61. Lehmann R, Zuellig RA, Kugelmeier P, Baenninger PB, Moritz W, Perren A, et al. Superiority of small islets in human islet transplantation. Diabetes. 2007;56:594-603. https://doi.org/10.2337/db060779 .

62. Giuliani M, Moritz W, Bodmer E, Dindo D, Kugelmeier P, Lehmann R, et al. Central necrosis in isolated hypoxic human pancreatic islets: evidence for postisolation ischemia. Cell Transplant. 2005;14:67-76. https://doi.org/10.3727/000000005783983287.
63. Yu Y, Gamble A, Pawlick R, Pepper AR, Salama B, Toms D, et al. Bioengineered human pseudoislets form efficiently from donated tissue, compare favourably with native islets in vitro and restore normoglycaemia in mice. Diabetologia. 2018;61:2016-29. https:// doi.org/10.1007/s00125-018-4672-5.

64. Penko D, Mohanasundaram D, Sen S, Drogemuller C, Mee C, Bonder CS, et al. Incorporation of endothelial progenitor cells into mosaic pseudoislets. Islets. 2011;3:73-9. https://doi.org/10.4161/ isl.3.3.15392.

65. Urbanczyk M, Zbinden A, Layland SL, Duffy G, Schenke-Layland K. Controlled heterotypic pseudo-islet assembly of human $\beta$-cells and human umbilical vein endothelial cells using magnetic levitation. Tissue Eng Part A. 2020;26:387-99. https://doi.org/10.1089/ ten.TEA.2019.0158.

66. Jiao A, Li F, Zhang C, Lv W, Chen B, Zhang J. Simulated cholinergic reinnervation of $\beta$ (INS-1) cells: antidiabetic utility of heterotypic pseudoislets containing $\beta$ cell and cholinergic cell. Int $\mathrm{J}$ Endocrinol. 2018;20:1505307-13. https://doi.org/10.1155/2018/ 1505307.

67. Arzouni AA, Vargas-Seymour A, Dhadda PK, Rackham CL, Huang GC, Choudhary P, et al. Characterization of the effects of mesenchymal stromal cells on mouse and human islet function. Stem Cells Transl Med. 2019;8:935-44. https://doi.org/10.1002/ sctm.19-0023.

68. Ito T, Itakura S, Todorov I, Rawson J, Asari S, Shintaku J, et al. Mesenchymal stem cell and islet co-transplantation promotes graft revascularization and function. Transplantation. 2010;89:1438-45. https://doi.org/10.1097/tp.0b013e3181db09c4.

69. Lebreton F, Bellofatto K, Wassmer CH, Perez L, Lavallard V, Parnaud G, et al. Shielding islets with human amniotic epithelial cells enhances islet engraftment and revascularization in a murine diabetes model. Am J Transplant. 2020;20:1551-61. https://doi. org/10.1111/ajt.15812.

70. Zafar A, Lee J, Yesmin S, Paget MB, Bailey CJ, Murray HE, et al. Rotational culture and integration with amniotic stem cells reduce porcine islet immunoreactivity in vitro and slow xeno-rejection in a murine model of islet transplantation. Xenotransplantation. 2019;26:e12508. https://doi.org/10.1111/xen.12508.

71.• Lebreton F, Lavallard V, Bellofatto K, Bonnet R, Wassmer CH, Perez L, et al. Insulin-producing organoids engineered from islet and amniotic epithelial cells to treat diabetes. Nat Commun. 2019;10:4491. https://doi.org/10.1038/s41467-019-12472-3 This study discusses the use of bioengineering organoids holding human islet and amniotic epithelial cells. These constructs, exploiting cellular immunomodulatory characteristics, have been demonstrated to ameliorate organoid function and engraftment in type 1 diabetes mouse model.

72. Essaouiba A, Okitsu T, Jellali R, Shinohara M, Danoy M, Tauran $\mathrm{Y}$, et al. Microwell-based pancreas-on-chip model enhances genes expression and functionality of rat islets of Langerhans. Mol Cell Endocrinol. 2020;514:110892. https://doi.org/10.1016/j.mce.2020. 110892.

73. Shik Mun K, Arora K, Huang Y, Yang F, Yarlagadda S, Ramananda Y, et al. Patient-derived pancreas-on-a-chip to model cystic fibrosis-related disorders. Nat Commun. 2019;10:3124. https://doi.org/10.1038/s41467-019-11178-w.

74. Glieberman AL, Pope BD, Zimmerman JF, Liu Q, Ferrier JP, Kenty JHR, et al. Synchronized stimulation and continuous insulin sensing in a microfluidic human Islet on a Chip designed for scalable manufacturing. Lab Chip. 2019;19:2993-3010. https://doi. org/10.1039/c91c00253g This study presents a thermoplastic, microfluidic-based pancreas-on-chip equipped with a synchronized stimulation and continuous insulin sensing.

75.• Jun Y, Lee J, Choi S, Yang JH, Sander M, Chung S, et al. In vivomimicking microfluidic perfusion culture of pancreatic islet spheroids. Sci Adv. 2019;5:eaax4520. https://doi.org/10.1126/sciadv. 
aax4520 This study presents a micro-channel chip device able to improve islet survival and function particularly if the islets are protected from shear stress.

76. Mohammed JS, Wang Y, Harvat TA, Oberholzer J, Eddington DT. Microfluidic device for multimodal characterization of pancreatic islets. Lab Chip. 2009;9:97-106. https://doi.org/10.1039/b809590f.

77. Lomasney AR, Yi L, Roper MG. Simultaneous monitoring of insulin and islet amyloid polypeptide secretion from islets of Langerhans on a microfluidic device. Anal Chem. 2013;85:7919 25. https://doi.org/10.1021/ac401625g.

78. Steurer W, Stadlmann S, Roberts K, Fischer M, Margreiter R, Gnaiger E. Quality assessment of isolated pancreatic rat islets by high-resolution respirometry. Transplant Proc. 1999;31:650. https://doi.org/10.1016/s0041-1345(98)01600-5.

79. Lehmann-Werman R, Neiman D, Zemmour H, Moss J, Magenheim J, Vaknin-Dembinsky A, et al. Identification of tissue-specific cell death using methylation patterns of circulating DNA. Proc Natl Acad Sci U S A. 2016;113:E1826-34. https://doi. org/10.1073/pnas.1519286113.

80. Lee SH, Hong S, Song J, Cho B, Han EJ, Kondapavulur S et al. Microphysiological analysis platform of pancreatic islet $\beta$-cell spheroids. Adv Health Mater 2018:7(2). Doi: 10.1002/ adhm. 201701111.

81. Goto M, Holgersson J, Kumagai-Braesch M, Korsgren O. The ADP/ATP ratio: a novel predictive assay for quality assessment of isolated pancreatic islets. Am J Transplant. 2006;6:2483-7. https://doi.org/10.1111/j.1600-6143.2006.01474.x.

82. Zbinden A, Marzi J, Schlünder K, Probst C, Urbanczyk M, Black S, et al. Non-invasive marker-independent high content analysis of a microphysiological human pancreas-on-a-chip model. Matrix Biol. 2020;85-86:205-20. https://doi.org/10.1016/j.matbio.2019.06.008.
83. Huh D, Matthews BD, Mammoto A, Montoya-Zavala M, Hsin HY, Ingber DE. Reconstituting organ-level lung functions on a chip. Science. 2010;328:1662-8. https://doi.org/10.1126/science. 1188302.

84. Bauer S, Wennberg Huldt C, Kanebratt KP, Durieux I, Gunne D, Andersson S, et al. Functional coupling of human pancreatic islets and liver spheroids on-a-chip: towards a novel human ex vivo type 2 diabetes model. Sci Rep. 2017;7:14620. https://doi.org/10.1038/ s41598-017-14815-w.

85. Tsvirkun D, Grichine A, Duperray A, Misbah C, Bureau L. Microvasculature on a chip: study of the endothelial surface layer and the flow structure of red blood cells. Sci Rep. 2017;7:45036. https://doi.org/10.1038/srep45036 This article presents a microfluidic capillary device capable to closely examine the distribution of red blood cells under physiological perfusion.

86. Ellis C, Ramzy A, Kieffer T. Regenerative medicine and cell-based approaches to restore pancreatic function. Nat Rev Gastroenterol Hepatol. 2017;14:612-28. https://doi.org/10.1038/nrgastro.2017. 93. This comprehensive review discusses advancements and pitfalls in cell-based regenerative medicine approach to restore pancreatic function. While much still needs to be done in this in order to obtain solid clinical results through cell-based therapies, the authors assume that in the next few years, there will be a rapid evolution especially through cell engineering and gene editing.

Publisher's Note Springer Nature remains neutral with regard to jurisdictional claims in published maps and institutional affiliations. 